\title{
A METHOD FOR FINDING SEA BREEZE DAYS UNDER STABLE SYNOPTIC CONDITIONS AND ITS APPLICATION TO THE SWEDISH WEST COAST
}

\author{
K. BORNE ${ }^{\mathrm{a}, *}$, D. CHEN ${ }^{\mathrm{a}}$ and M. NUNEZ ${ }^{\mathrm{b}}$

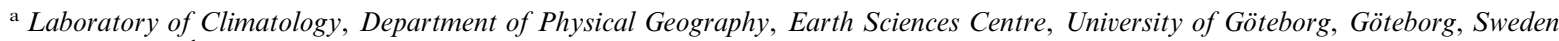 \\ ${ }^{\mathrm{b}}$ Department of Geography and Environmental Studies, University of Tasmania, Tasmania, Australia \\ Received 30 May 1997 \\ Revised 19 January 1998 \\ Accepted 31 January 1998
}

\begin{abstract}
A method for selecting sea breeze days in an archipelago was developed with special application to the West Coast of Sweden. The primary criterion for identifying a sea breeze was the occurrence of a distinct change in surface wind direction within a $24 \mathrm{~h}$ period. The data used in the study were gathered using hourly meteorological records from field stations situated on the West Coast. Six different filters were included in the method; each of them developed from empirical knowledge of the physical processes responsible for the occurrence of a sea breeze system. Using this method it is possible to create a data set of sea breeze days, which does not use distance to the shoreline as a necessary condition for classification. (c) 1998 Royal Meteorological Society.
\end{abstract}

KEY WORDS: archipelago area; south-western Sweden; selection of sea breeze; sea breeze

\section{INTRODUCTION}

The work represented here is part of a programme to study the characteristics, onset and physical mechanisms of sea breezes in the archipelago area of south-western Sweden. An initial requirement is the establishment of a database for sea breeze days. However this is difficult given the nature of the archipelago and the lack of clearly defined sea-land boundaries. In this paper we present an easy and practical method for selection of sea breeze days in this complex environment.

The sea breeze has often been studied through a theoretical approach using analytical and numerical modelling, as for example Neumann and Mahrer (1971), to study the physical processes responsible for the sea breeze development. To verify the analytical and numerical models simulating the sea breeze, observational mesoscale studies mainly in straight coastal areas with smooth topography have been used. Later models take into consideration the sea breeze development in complex environments, as for example Mahrer and Pielke (1977) who studied the effect of topography on sea and land breezes in a 2-D numerical model and Xian and Pielke (1991) who simulated the effect different width of landmasses have on the sea breeze development. Recently some observational studies on sea breeze circulation in areas with complex heating have been presented, as for example Zhong and Takle (1992). In general, emphasis has been on sea breeze development as a mesoscale feature rather than a locally dominated circulation system.

Observational studies are useful in that they provide experimental data in what could be complex surface and upper air conditions. Therefore they have an important role to play in model validation and in clarification of physical mechanisms. However, deriving a purely observational data set in an archipelago environment is a difficult task for the reasons already outlined. As a result, there have been

\footnotetext{
* Correspondence to: Department of Physical Geography, Earth Sciences Centre, University of Göteborg, Box 460, SE-40530 Göteborg, Sweden. Tel.: + 4631 7731962; fax: + 4631 7731986; e-mail: Katarina@gvc.gu.se
}

CCC 0899-8418/98/080901-14\$17.50

(C) 1998 Royal Meteorological Society 
only a few observational studies in complex coastal environments, for example Physick and Byron Scott (1977), Banta (1995) and Gustavsson et al. (1995), so that model validation is largely lacking for such an environment.

In this study, a novel approach was developed for characterising sea breeze events. The emphasis is on the outstanding features of the time series at individual stations rather than spatial interrelationships between individual stations and the complex coastline. The approach is deliberately simple, and mostly based on observational data on wind speed and wind direction. Further studies will concentrate on the physical processes responsible for the sea breeze development. Therefore, it is of interest here to produce a data set that is as independent as possible from the techniques developed in these future studies. The produced data set is also suitable for model validation. The selection criterion used in this method is as general as possible, therefore allowing different local features of the sea breeze to be selected. In addition, the method can with some minor modifications easily be applied to different environments.

In section two the selection method will be presented. Section three contains an application of the method to the Swedish West Coast and section four evaluates the method. The last section presents a discussion and conclusions.

\section{METHOD}

Different sea breeze criteria have been used to define sea breeze days. From the literature, the sea breeze is characterised by different criteria depending on the collected data and the geographical position. There, the first criterion for sea breeze days is to exclude days with large synoptic variations. The second criterion is based on the prerequisite of sea breeze development, i.e. that there must be a temperature difference between sea and land. A criterion that is also used is the occurrence of an upper return flow as for example by Lyons and Olsson (1972), who also use the detection of a sea breeze front as a criterion. Brittain (1978) stated another criterion, namely that the onshore component of the surface wind must exceed the onshore component of the free-stream wind for the event to be classified as a sea breeze. At St. John's, Newfoundland, Banfield (1991) used a rapid change in surface wind direction during a $24 \mathrm{~h}$ period as the first criterion for the sea breeze onset. The new wind direction would be onshore and distinct from the synoptic wind.

In the study by Gustavsson et al. (1995) the sea breeze must be defined with reference to a 'local shoreline' in the archipelago, which makes the criterion unnecessarily complex. One of the most difficult problems to solve is to find a way of defining the location of the shoreline in an archipelago. In this study, the principal criterion is to recognise a sea breeze, as the occurrence of a distinct reversal of the surface wind direction within $24 \mathrm{~h}$, not attributed to synoptic scale circulation.

The method presented in this paper consists of six filters containing different conditions that must be fulfilled before the day is accepted as a sea breeze day. The filters are developed from empirical studies of the characteristic features of the sea breeze using data from field stations and radiosondes. The wind speed and wind direction at $700 \mathrm{hPa}$ level from radiosondes is used as a measure for the general synoptic condition. It will be referred to as geostrophic wind in this paper. The first and second filters are constructed to exclude days with probable large changes in synoptic conditions. The third filter excludes days with too strong synoptic winds. Filter 4 ensures that there is a reasonably large temperature difference between sea and land at the chosen sea breeze day. Filter 5 uses the characteristic change in surface wind direction at the onset of the sea breeze as a selection tool. Filter 6 uses a ratio between the change in surface wind direction and a mean value of wind direction change in the stable air that occurs directly after the onset of the sea breeze.

The filters together represent a simple sea breeze criterion and can be used at every field station in the archipelago without having to define the shoreline. The method also accepts sea breeze days with small changes in wind direction compared to the geostrophic wind. Another feature of the method is that it is constructed in such a way that it allows comparison between stations and between different seasons. 


\subsection{Detailed description of the filters}

The method consists of six filters containing different conditions that must be fulfilled before the day is accepted as a sea breeze day. An outline of the scheme is presented in Figure 1. To create data that can easily be compared, the change of wind speed and wind direction over time is used, rather than their

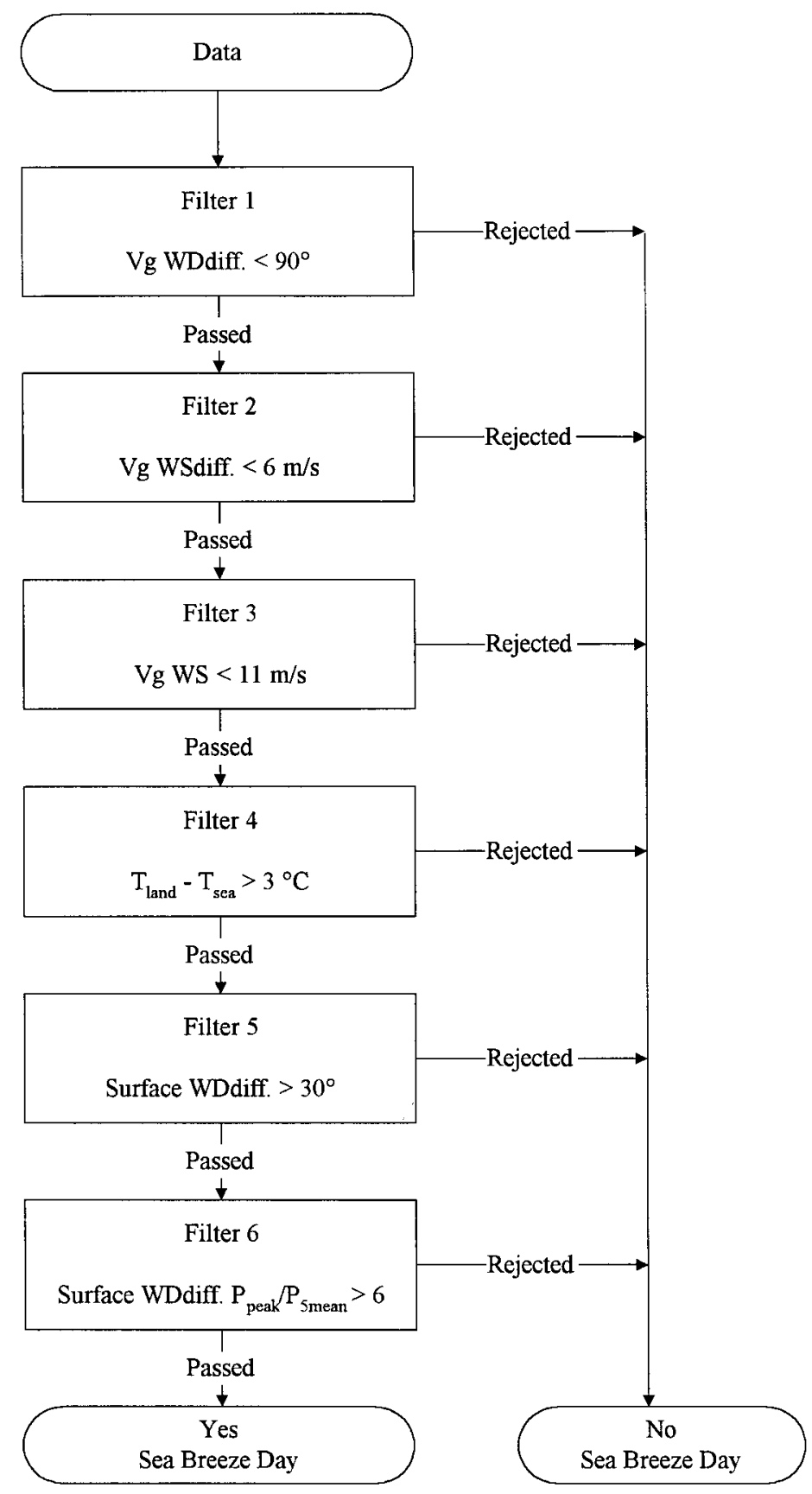

Figure 1. Flow diagram showing the different filters used in the technique. The symbol ' $V_{\mathrm{g}} \mathrm{WD}_{\text {diff.' }}$ ' represents the change in geostrophic wind direction, ' $V_{\mathrm{g}} \mathrm{WS}_{\text {diff.' }}$ ' represents the geostrophic wind speed. ' $T_{\text {land }}$ ' and ' $T_{\text {sea }}$ ' are the daily maximum temperature at field station 3 and the sea-surface temperature at field station, respectively. 'Surface $\mathrm{WD}_{\text {diff. }} P_{\text {peak }} / P_{5 \text { mean }}$ ' represents the ratio between a sharp change in wind direction $\left(P_{\text {peak }}\right)$ and the average hourly changes in wind direction in the $5 \mathrm{~h}$ following the $P_{\text {peak }}$ $\left(P_{5 \text { mean }}\right)$ 
absolute values. The change in wind direction is also calculated to show the smallest possible change during $1 \mathrm{~h}$, i.e. the maximum change is $180^{\circ}$. Also, there is no concern whether the wind direction is turning clockwise or anticlockwise. In the design of the six filters, the variability of the data was systematically studied for each filter individually. In particular the sensitivity of filters 5 and 6 , which use the characteristics of the surface sea breeze wind, is carefully analysed. The filters are then calibrated to fit the study area used in this paper. The calibration implies iterating with different filter criteria until correct results are obtained, when the filters are applied to the reference data set selected (presented later in 3.2). A more detailed description concerning the development of each filter is presented below.

Filter 1: $V_{\mathrm{g}}: \mathrm{WD}_{\text {diff. }}<90^{\circ}$ during $24 \mathrm{~h}$ where $V_{\mathrm{g}}$ is the geostrophic wind and $\mathrm{WD}_{\text {diff }}$ is the change in the geostrophic wind direction during the specified time. The first filter excludes days with large changes in wind direction at the $700 \mathrm{hPa}$ level during $24 \mathrm{~h}$. The change in wind direction is not allowed to be larger than $90^{\circ}$, and is calculated as the change between 13:00 h LST the previous day and the actual day at 13:00 h LST. Stable synoptic conditions are a criterion for the sea breeze development, nevertheless a change in wind direction of $90^{\circ}$ or less during $24 \mathrm{~h}$ is generally acceptable. The sensitivity of this filter is therefore allowed to be rather low. By using the data at 13:00 h LST, the possibility of the wind at 700 $\mathrm{hPa}$ level being influenced by the sea and land breeze altering wind direction, is avoided.

Filter 2: $V_{\mathrm{g}}: \mathrm{WS}_{\text {diff. }}<6 \mathrm{~m} / \mathrm{s}$ during $12 \mathrm{~h}$ where $V_{\mathrm{g}}$ is the geostrophic wind and $\mathrm{WS}_{\text {diff. }}$ is the change in the geostrophic wind speed during the specified time. The second filter also relates to the upper wind flow by excluding days with a change in synoptic wind speed higher than $6 \mathrm{~m} / \mathrm{s}$ during $12 \mathrm{~h}$ (from 01:00 to 13:00 h LST) at the $700 \mathrm{hPa}$ level. The change in synoptic wind speed of $6 \mathrm{~m} / \mathrm{s}$ during $12 \mathrm{~h}$ as well as the figure of $90^{\circ}$ change in synoptic wind direction presented above are results from the calibration, but still small enough to exclude days with rapid changing synoptic conditions. Together, these two filters reject all days where the requirement of the stable synoptic circulation conditions, which is a first criterion for the development of a sea breeze, is not met.

Filter 3: $V_{\mathrm{g}}: \mathrm{WS}<11 \mathrm{~m} / \mathrm{s}$ at 13:00 h LST where $V_{\mathrm{g}}$ is the geostrophic wind and WS is the $700 \mathrm{hPa}$ wind speed at the specified time. The third filter is there to exclude days with a too strong synoptic wind speed. The limit of $11 \mathrm{~m} / \mathrm{s}$ is an approximation taken from the literature where, for example Savijärvi and Alestalo (1988) simulated the sea breeze development and found that the sea breeze was eliminated by synoptic conditions if the geostrophic wind speed exceeded $8 \mathrm{~m} / \mathrm{s}$. The study presented by Arritt (1992) modelled the geostrophic wind speed limit to be $11 \mathrm{~m} / \mathrm{s}$ over which the sea breeze did not develop.

Filter 4: $T_{\text {land }}-T_{\text {sea }}>3^{\circ} \mathrm{C}$ during $24 \mathrm{~h}$ where $T_{\text {land }}$ is the daily maximum temperature at an inland station and $T_{\text {sea }}$ is the sea surface temperature from a coastal station. The fourth filter represents the temperature difference between sea and land that develops during a sea breeze day. From Watts (1955) it has been noted that a sea breeze can develop even if the land/sea temperature difference is very small (as low as $2^{\circ} \mathrm{C}$ ). In this work we use the sea surface temperature as an approximation for the air temperature over water. The sea surface temperature is measured at one station and is held to be representative for the total archipelago area. This approximation creates a potential source of error due to lack of temporal and spatial sea surface temperature data. To ensure that the fourth filter only selects days with potential for sea breeze development, it is concluded that a temperature difference between land/sea of at least $3^{\circ} \mathrm{C}$ is necessary for the day to be accepted as a possible sea breeze day.

Filter 5: Surface: $\mathrm{WD}_{\text {diff. }}>30^{\circ}$ during the hours from (sunrise $+1 \mathrm{~h}$ ) to (sunset $-5 \mathrm{~h}$ ). When synoptic conditions are favourable and there is a temperature difference between land and sea, a quick change in the surface wind direction is the most distinct characteristic feature of the sea breeze. By calculating the change in surface wind direction (over $1 \mathrm{~h}$ ) during daytime, the possible sea breeze days are selected using the condition that the change in wind direction during $1 \mathrm{~h}$ must be larger than $30^{\circ}$. In contrast to most other observational studies, sea breeze days are here analysed without taking the direction of the geostrophic wind into consideration. Therefore, it is difficult to verify the used threshold of $30^{\circ}$ in the literature. But this change in surface wind direction exceeds the change in wind direction occurring during the day by Ekman-veering $(1000 \mathrm{hPa}-700 \mathrm{hPa})$. The filter does not take into consideration the direction of the change. 
Filter 6: Surface $\mathrm{WD}_{\text {diff: }}: P_{\text {peak }} / P_{5 \text { mean }}>6$ during the hours from (sunrise $+1 \mathrm{~h}$ ) to (sunset) where $P_{\text {peak }} / P_{5 \text { mean }}$ is the ratio between a sharp change in wind direction $\left(P_{\text {peak }}\right)$ and $P_{5 \text { mean }}$ which is the average of the hourly changes in wind direction in the $5 \mathrm{~h}$ following the $P_{\text {peak }}$. The sea breeze is characterised not only by a change in wind direction as seen in filter 5 , but also by the following five-hour period of non-veering wind conditions. Filter 6 states that for sea breeze days the ratio $P_{\text {peak }} / P_{5 \text { mean }}$ is larger than six during the daytime hours. This will exclude days with strong veering conditions not connected to the sea breeze, and also sea breeze days with very short duration time. By systematically analysing the character of the ratio during sea breeze days in the reference data set (presented later in 3.2), a threshold value of 6 is found. Filter 6 is now calibrated to fit the study area. The sensitivity of filter 6 is further discussed in 3.3 and illustrated in Figure 5. By using filters 5 and 6 together, the sea breeze is characterised as a distinct change in wind direction of at least $30^{\circ}$ followed by $5 \mathrm{~h}$ of stable conditions in wind direction.

\subsection{Method assumptions}

Several assumptions are made in the development of this selection method. One assumption is that the quick change in wind direction at the $10 \mathrm{~m}$ level is due to the onset of a sea breeze and is not due to any other local wind. The assumption appears reasonable, since the area is rather smooth in topography and any mountain and valley winds or cold air drainage flow cannot be responsible for the change in wind direction seen at the field station. The method is also constructed to allow for several different sea breeze characteristics such as, for example, sea breeze veering and different times of onset. One characteristic feature that could be overlooked is the pulsating nature of the sea breeze, typically lasting from 10 to 20 min in its period. However these are not expected to influence the sea breeze criterion developed here based on hourly averages of wind direction. The method uses the establishment of the sea breeze during daytime, specifically between $1 \mathrm{~h}$ after sunrise and $1 \mathrm{~h}$ before sunset. Added to this is the demand for stable wind direction conditions for $5 \mathrm{~h}$ after onset. It is possible that sea breezes, which develop in the very late afternoon, will be rejected in the selection process. This is of concern in early spring and late autumn where the days are rather short.

The method depends on access to data concerning the synoptic conditions in the actual area. In this study radiosonde data measured every $12 \mathrm{~h}$ is used. With higher frequency data, approximately every 6 $\mathrm{h}$, the accuracy of filters 1, 2 and 3 could increase. Because the criterion is rather sharply defined, some sea breeze days will not pass through the filters and therefore the method will underestimate the sea breeze frequency. Nevertheless the rather small data set that will have passed all six filters, will provide ideal conditions for process studies on sea breeze development in a complex environment.

\section{APPLICATION OF THE METHOD}

The method is applied in a region, which includes the city of Göteborg and an archipelago area to the north of the city in sections 3.1 and 3.2. A short description of the study area is presented together with the time period and the different field stations used in this study. Section 3.3 discusses the response to the occurrence of a sea breeze by different filters.

\subsection{Study area}

The county of Bohuslän, on the West Coast of Sweden can generally be described as a landscape produced by glacial processes, with rather undramatic topography varying from sea level to approximately $150 \mathrm{~m}$ a.s.l. and very distinct fissure valleys. The archipelago comprises islands that vary in size between 1 and $150 \mathrm{~km}^{2}$. On the sea side, the archipelago is strongly characterised by granite and gneiss rocks that formed in large roche moutonnées which hold very little vegetation. The inland area is 


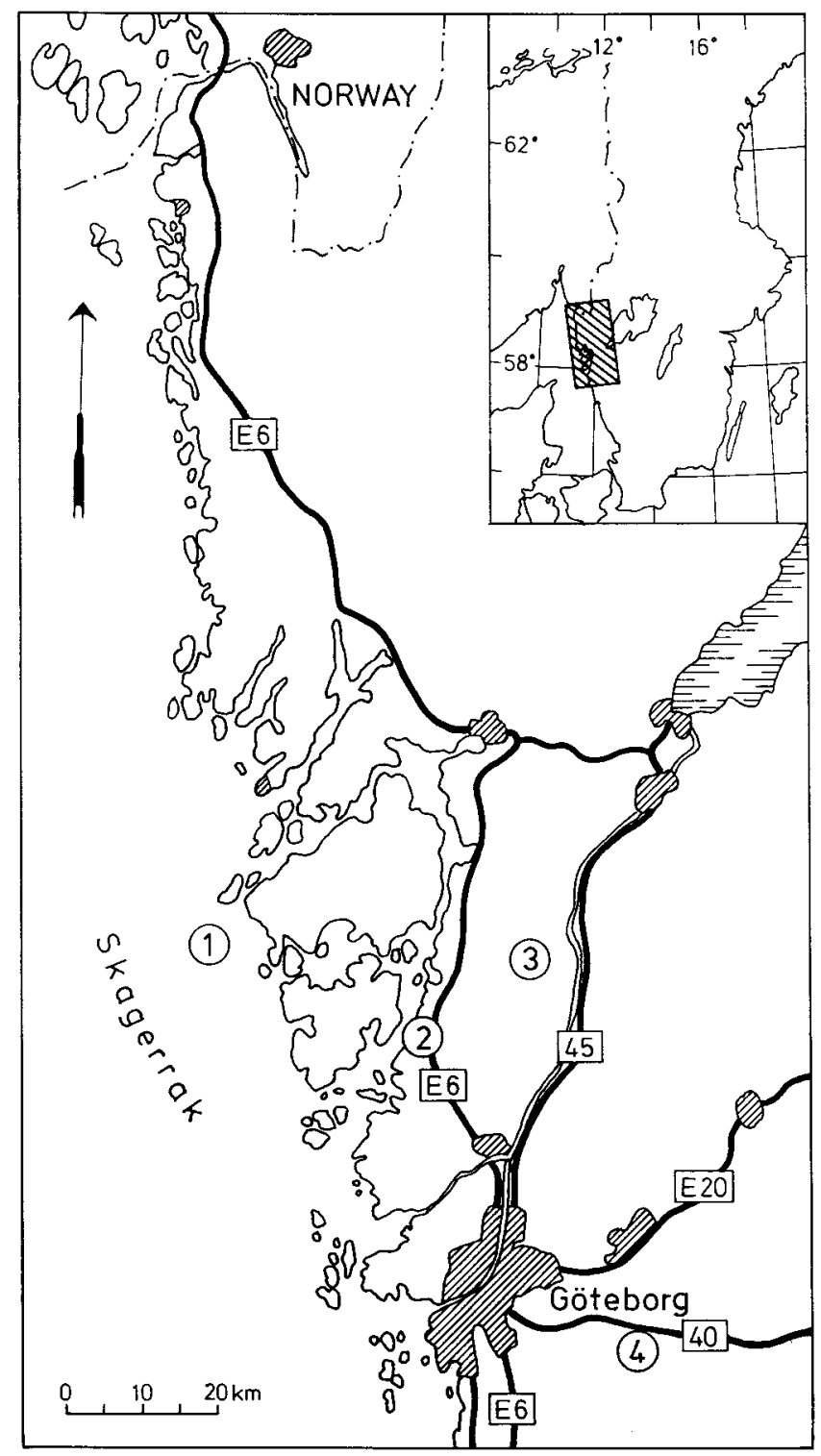

Figure 2. Map of the study area showing field stations 1, 2, 3 and 4 . All stations record $1 \mathrm{~h}$ average wind speed and wind direction at $10 \mathrm{~m}$. In addition, all stations also record $1 \mathrm{~h}$ average temperatures. Upper air observations are recorded at Landvetter airport, shown at field station 4

dominated by moraine and clay deposits with more dense vegetation than on the coast. The study area is positioned north of latitude $58^{\circ}$, longitude $12^{\circ}$, and faces the Skagerack Sea to the west, as presented in Figure 2.

\subsection{Observations and synoptic overview}

The filters are developed from empirical studies of the characteristic features of the sea breeze using 10 min average data as well as $1 \mathrm{~h}$ average data from field stations and radiosondes, as presented in Figure 2. July 1994 was investigated to find the features that could be used to select days with sea breezes. After a very cold spring the sea had not warmed up and the sea temperature was approximately $15^{\circ} \mathrm{C}$ in the beginning of July rising to $21^{\circ} \mathrm{C}$ at the end of the month. Therefore, the summer could give rise to many 
well-developed sea breeze days. Several high-pressure situations with clear skies and high air temperatures were characteristic of the weather during that month. Only days with stable synoptic conditions were used to study the surface characteristics of the sea breeze development, i.e. features used in filters 4,5 and 6 . The method uses $1 \mathrm{~h}$ mean surface wind speed and wind direction at $10 \mathrm{~m}$ height from field station 2 located near the coast. The temperature difference was calculated using the sea surface temperature measured approximately every third day at a meteorological station (field station 1), and the $1 \mathrm{~h} \mathrm{mean}$ maximum temperature measured at the inland field station 3 approximately $20 \mathrm{~km}$ from the coastline. The synoptic conditions were represented by radiosonde data of wind speed and direction from the $700 \mathrm{hPa}$ level measured every $12 \mathrm{~h}$ at field station 4 .

\subsection{Sea breeze detection}

Generally the first four filters only decide the background conditions suitable for sea breeze development while filters 5 and 6 are based on the behaviour of surface winds during sea breeze onset. Figure 3 represents the different steps used in the method to detect a well-developed sea breeze day, the 19 July 1994. The geostrophic wind was blowing continuously at $7.5 \mathrm{~m} / \mathrm{s}$ from the northeast, which resulted in the passing of filters 1,2 and 3 without rejection. The temperature difference was large, approximately $8^{\circ} \mathrm{C}$. Figure 3(a) and (b) illustrates the behaviour of wind speed and direction at the coastal field station. A sharp change in wind direction occurred in the early morning about 08:00 h LST as may be seen in Figure 3 (c) with the veering of the wind of about $120^{\circ}$. The last filter passes days with a quick change in wind direction followed by a period of non-veering wind. This is characterised by the ratio $P_{\text {peak }} / P_{5 \text { mean }}$ which is seen in Figure 3(d) as a sharp peak $>6$.

Together, the filters provide detailed requirements for acceptance of sea breeze conditions, demanding stable conditions for the geostrophic wind at the $700 \mathrm{hPa}$ level, a temperature difference and a distinct change in wind direction followed by a non-veering period. Several 'clear' sea breeze days judged from traditional criterion (section 2), such as the 6 July (Figure 4) were therefore rejected. Figure 4(a) shows a change in wind direction of almost $180^{\circ}$ on the $6 \mathrm{July}$, followed by a rather stable period. The rejection is explained in Figure 4(b) where it is seen that there is no peak connected to the change in wind direction. Here, the change in wind direction was not as distinct as filter 6 demanded. But because the filters are difficult to satisfy, the method makes the selected data secure in the sense that there is little doubt regarding the accuracy of the selected days being sea breeze days. Figure 5 shows the wind ratio $P_{\text {peak }} / P_{5 \text { mean }}$ for six different sea breeze days. Filter 6 allows days with a peak ratio higher than six to pass the filter. In Figure 5 it can be seen that here, 3 days will be rejected (6 July, 20 July and 28 July).

The question may be asked as to how reliable these criteria are in the selection of sea breeze days. Most of the non-sea breeze days are definitely excluded from the method by one of the last three filters. The accuracy of the method is evaluated in the following section 4 .

\section{EVALUATION OF THE METHOD}

The method developed here was evaluated by comparison with an independent selection of sea breeze days. The selection were performed by an experienced researcher at the Department of Physical Geography, University of Lund, Sweden based on usual observations of surface wind speed and wind direction, upper air winds and surface air temperature. The periods from 1 May to 31 June 1992 and from 1 June to 31 August 1993 were used for the evaluation. The two selections are processed simultaneously without knowledge of each other and give the opportunity to decide the accuracy of the method presented.

Table I presents the results from the two different selection processes. In selection L, performed by the Department of Physical Geography, University of Lund (hereafter called the 'Lund method') days are distributed into three categories: (a) sea breeze; (b) possible sea breeze; and (c) no sea breeze. The first category is defined as days with a distinct change in wind direction during the day followed by a reversal 
during the night. An increase in wind speed is connected to the change in wind direction and the day also presents a positive temperature difference between land and sea. The second category is used when the geostrophic wind direction coincides with the direction of the sea breeze, and there is no clear change in wind direction that solely can be explained by a sea breeze development. The third category includes days with very small changes in the wind direction, days with an inconsistent wind direction after the sea breeze

a

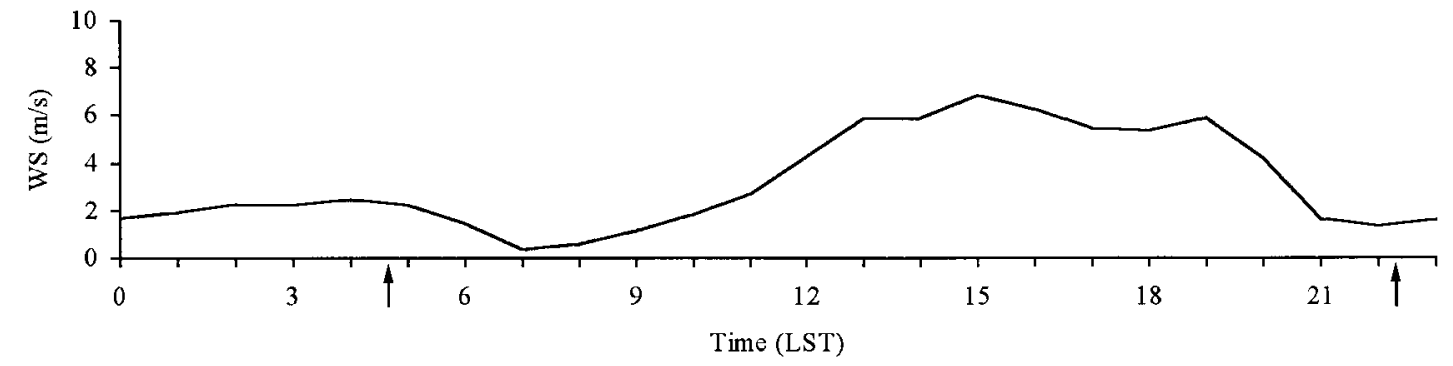

b

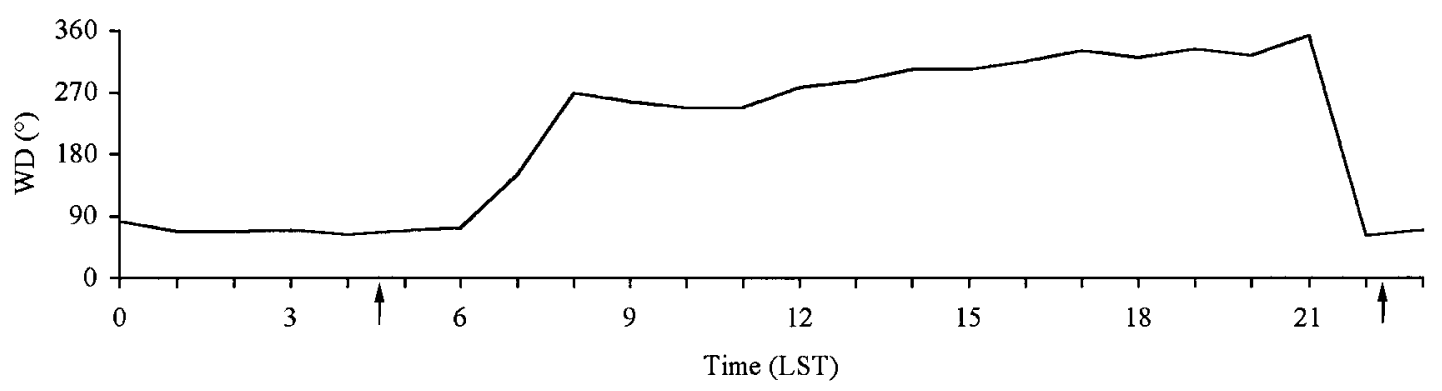

C

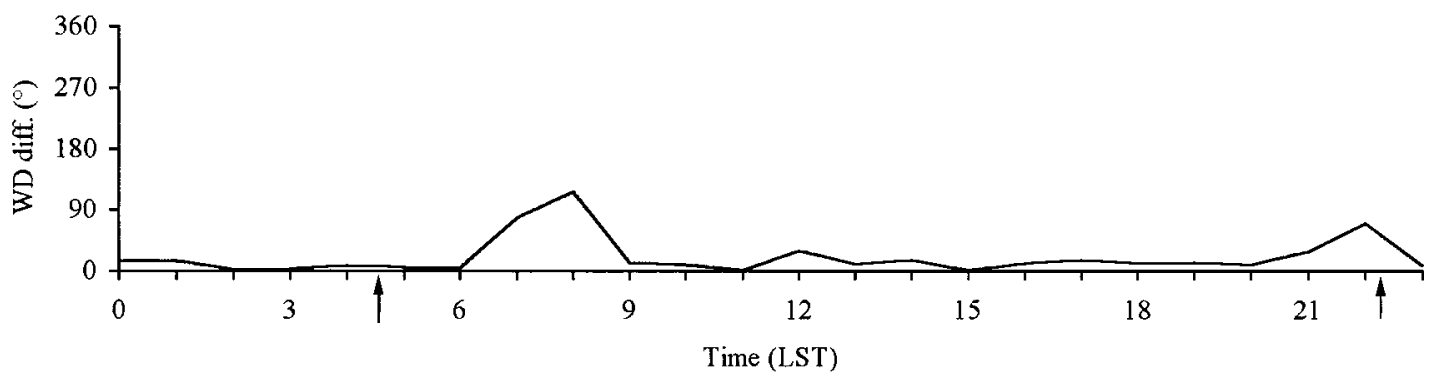

$\mathrm{d}$

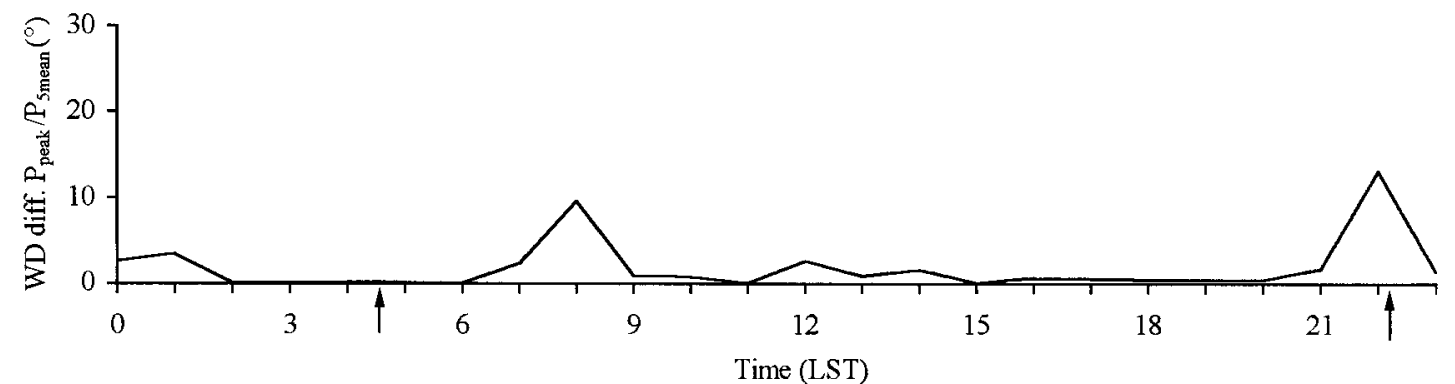

Figure 3. Characteristics of wind speed and wind direction for a day that was selected as a sea breeze day by the filter method. Data was collected on 19 July 1994 at field station 3. The arrow illustrates sunrise and sunset 
a

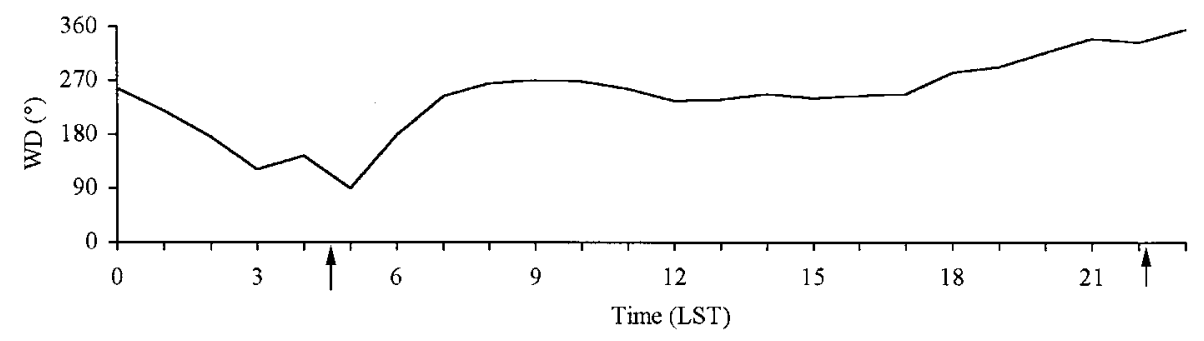

b

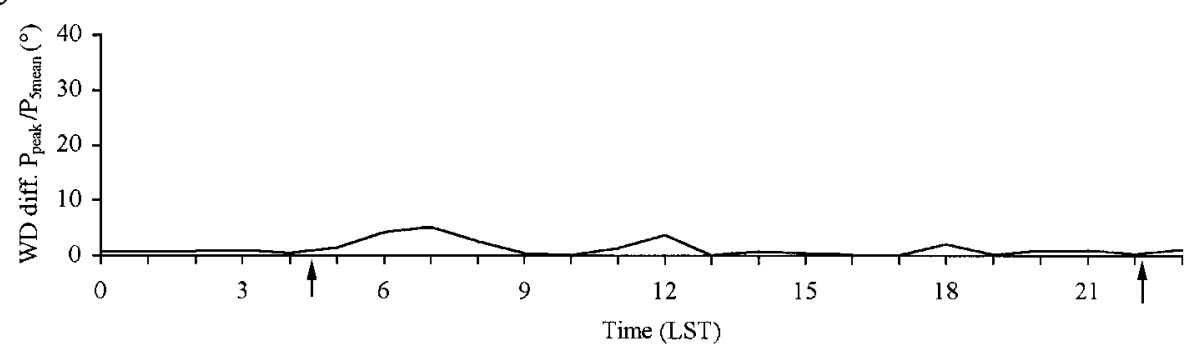

Figure 4. Characteristics of wind direction for a day that was rejected by the filter method. Based on the traditional criteria (section 2), this day is considered to be a sea breeze day. The arrow illustrates sunrise and sunset

wind shifts, days with very small temperature differences between land and sea and days with very high wind speeds. In the selection method constructed by the authors, hereafter called the 'filter method'; days are only distributed into two categories, sea breeze or non-sea breeze.

\subsection{Statistics}

Table I presents the extent of the selected data set including days from May to August over different years. The filter method selects 22 days as sea breeze days, while the Lund method selects 50 days as sea breeze days out of a total of 130 days. To evaluate the accuracy of the filter method we can compare the two independent selections. Of the 22 days selected by the filter method as sea breeze days, the Lund method gave the following distribution: (a) sea breeze, 17 days; (b) possible sea breeze, 3 days; and (c) no sea breeze, 2 days.

Alternatively, the filter method can be evaluated against the days that the Lund method established as 'sea breeze', 'possible sea breeze' and 'no sea breeze', presented in section 4 as categories (a), (b) and (c). Of the 50 days that were divided into category (a) by the Lund method, the filter method only found 17 days; out of the 36 days of category (b) by the Lund method, the filter method obtained 3; and only 2 days were found as non-sea breeze (category (c)) by the filter method as compared to 44 by Lund. From these studies it can be stated that the constructed selection method has an accuracy of more than $75 \%$ in the process of selecting sea breeze days.

\subsection{Filter analysis}

The filter method is sharply defined and there were many days accepted by the Lund method as sea breeze that were rejected by the Filter method. Therefore, it is of interest to study the strength of each filter and its interaction in the selection process. This can easily be done using as a database the 50 days selected by the Lund method as being sea breeze days. Table II shows the successive process of rejection for these 50 sea breeze days. Filters 1 and 4 are effective in the rejection process, while filters 5 and 6 only reject one or two days.

Table III groups all sea breeze days as selected by each filter, and partitions these days into 'sea breeze', 'possible sea breeze' and 'no sea breeze', as given by the Lund method. It may be noticed that the selection 
properties of the first three filters are quite different from the last three. It can also be noted that filters 1 and 2 are almost equally good at selecting sea breeze days as they are at selecting non-sea breeze days.

The character of the method is deliberately simple, as the objective is to produce a data set that is as independent as possible from the physical processes responsible for the sea breeze development. The selection method should also allow different local features, which could be a property of sea breeze development in the archipelago. This will create filters that are designed to reject days with bad sea breeze conditions rather than select sea breeze days distinctly. Table IV shows the number of days rejected by the filters. Filter 5 has the highest rate of rejection of non-sea breeze days followed by filters 4 and 6 . The rejection of sea breeze days is generally low, with the lowest number in filter 5. Filters 4 and 6 have the highest rates of sea breeze day rejection. Therefore it can be concluded that the most important filters for
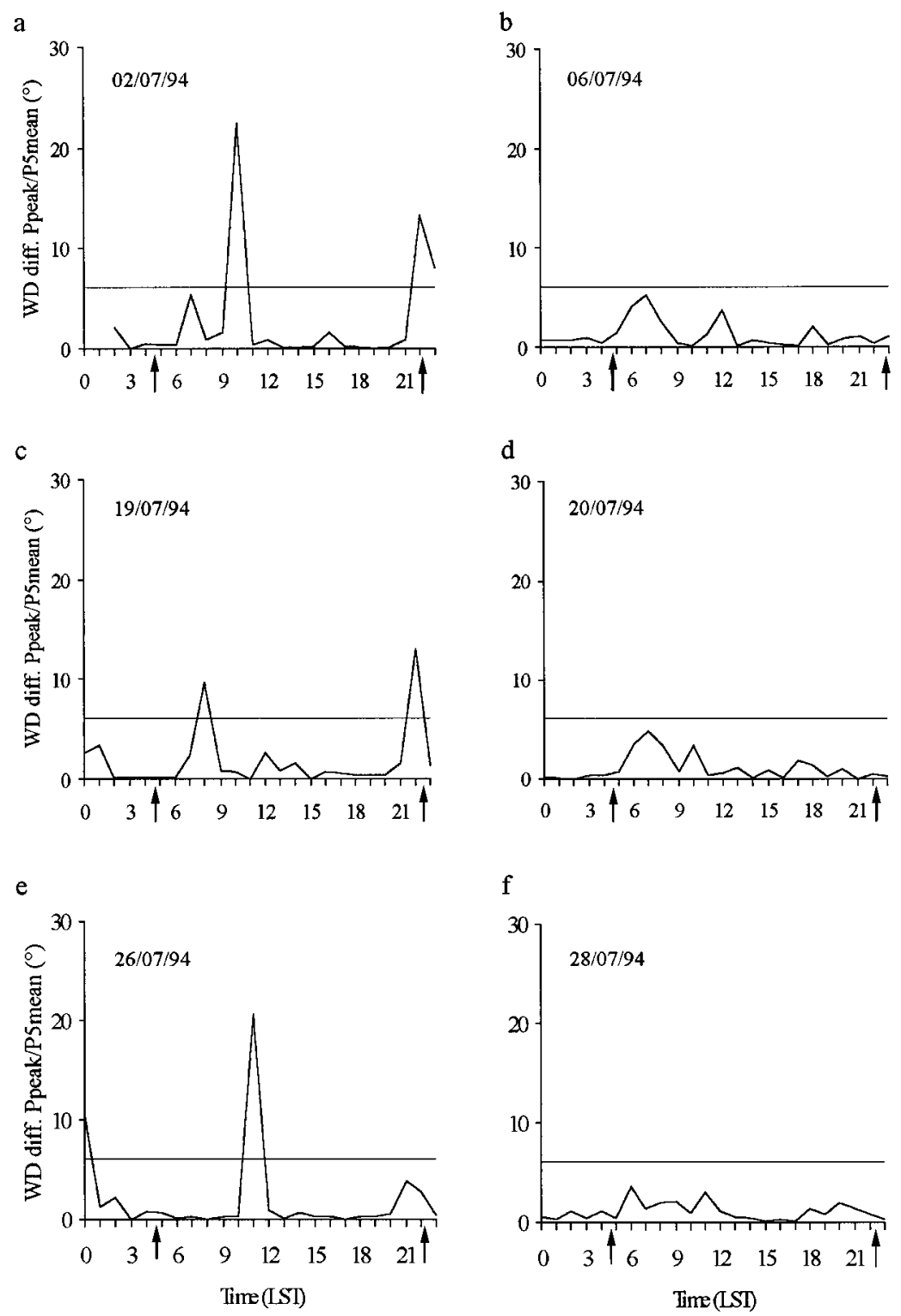

Figure 5. Sea breeze days (a) 2 July; (b) 6 July; (c) 19 July; (d) 20 July; (e) 26 July and (f) 28 July 1994 with varying wind ratio $\left(\mathrm{WD}_{\text {diff. }} . P_{\text {peak }} / P_{\text {mean }}\right)$. Only 3 days pass filter 6 . The line illustrates the threshold value above which sea breeze conditions are accepted. The arrow indicates the sunrise and sunset 
Table I. Summary showing how the filter method (F) compared with the Lund method (L) for the 5 months covered by this study. Vertical hatched lines represent prediction of a sea breeze event, and possible sea breezes are tilted lines. No sea breeze predictions are blank. Only 17 days were simultaneously classified as sea breezes by both methods

\begin{tabular}{|c|c|c|c|c|c|c|c|c|c|c|}
\hline Day & $\frac{\mathrm{L}}{92-05}$ & $\frac{F}{92-05}$ & $\frac{\mathrm{L}}{92-06}$ & $\frac{F}{92-06}$ & $\frac{\mathrm{L}}{93-06}$ & $\frac{F}{93-06}$ & $\frac{\mathrm{L}}{93-07}$ & $\frac{F}{93-07}$ & $\frac{\mathrm{L}}{93-08}$ & $\frac{F}{93-08}$ \\
\hline 1 & - & - & & & - & - & - & - & & \\
\hline 2 & - & - & & & - & - & - & - & & \\
\hline 3 & - & - & & & - & - & & & & \\
\hline$\overline{4}$ & - & - & & & - & $\overline{-}$ & & & & \\
\hline 5 & - & - & IIIII & 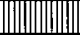 & - & - & & & & \\
\hline 6 & & & & & - & - & & & & \\
\hline 7 & & & & & - & - & & & & \\
\hline 8 & & & & & - & - & 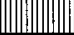 & & & 明 \\
\hline 9 & & & & & - & - & & & & \\
\hline 10 & & & & & - & - & & & & \\
\hline 11 & & \|\|\|\| & & & - & - & & & & \\
\hline 12 & & & & & - & - & $\mathbb{U} \mathbb{P}$ & & & \\
\hline 13 & & & & & - & - & & & & \\
\hline 14 & & & & & & & UIIII & & & \\
\hline 15 & & & & & |nس & & & & & \\
\hline 16 & & & & & & & & & & \\
\hline 17 & & & & & & & $\|$ & & & \\
\hline 18 & & & & & & & & & & \\
\hline 19 & & & & & & & & & & \\
\hline 20 & & \|\| & & & & & & & & \\
\hline 21 & & & & & & & & & & \\
\hline 22 & & & & & & 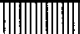 & m & & & \\
\hline 23 & & & & & & & $=$ & - & & \\
\hline 24 & & $|\|||||||| \mid$ & & & & & - & - & & \\
\hline 25 & & & & 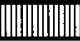 & & & & & & \\
\hline 26 & & & & & & & & & & \\
\hline 27 & & & & & & & & & & \\
\hline 28 & & & & & & & & & & 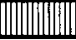 \\
\hline 29 & & & & & $\|$ & $\| 1 \mid$ & & & & \\
\hline 30 & & & and & & - & - & & & & \\
\hline 31 & |f||. & 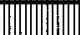 & - & - & - & - & & & & \\
\hline
\end{tabular}

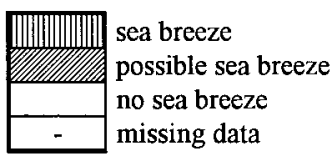

Table II. Flow diagram showing how the filter method processed the 50 days classified as sea breezes by the Lund method. Filters 1 and 4 have the highest number of rejections

\begin{tabular}{|c|c|c|c|c|c|c|c|c|}
\hline Filter & Input & $\mathrm{F} 1$ & $\mathrm{~F} 2$ & F3 & $\mathrm{F} 4$ & F5 & F6 & Output \\
\hline Selected & 50 & $\Rightarrow \downarrow$ & $\Rightarrow \downarrow$ & $\Rightarrow \downarrow$ & $\Rightarrow \downarrow$ & $\Rightarrow \downarrow$ & $\Rightarrow \downarrow$ & $\Rightarrow 17$ \\
\hline Rejected & & -10 & -4 & -6 & -10 & -2 & -1 & \\
\hline
\end{tabular}

producing a sea breeze data set by rejecting days with bad sea breeze conditions are filters 4,5 and 6 . At the same time filters 4 and 6 are also highly represented in rejecting good sea breeze days.

To be able to study the overlap between different filters, a matrix for the selected sea breeze days as well as for the rejected non-sea breeze days is constructed. Table $\mathrm{V}$ shows the overlap matrix for the selected sea breeze days. The connection between the filters is tested by documenting how many times the sea 
Table III. Comparison of sea breeze days as selected by each filter versus the evaluation of the Lund method. For example at filter 1, 109 days passed as sea breeze days. These 109 days were partitioned as sea breeze days (41); possible sea breeze days (30); and no sea breeze days (38) by the Lund method

\begin{tabular}{llllll}
\hline Filter & \multicolumn{2}{l}{ Filter method } & & \multicolumn{2}{l}{ Lund method } \\
\cline { 2 - 3 } \cline { 5 - 6 } & Total days selected as sea breeze by the method & Sea breeze & & Possible sea breeze & Non sea breeze \\
\hline 1 & 109 & 41 & 30 & 38 \\
2 & 109 & 43 & 28 & 38 \\
3 & 85 & 42 & 35 & 20 & 23 \\
4 & 70 & 47 & 14 & 8 \\
5 & 75 & 38 & 15 & 21 \\
6
\end{tabular}

breeze day passes filters 1 and 2, filters 1 and 3, and continuing through the sixth filter. Table $\mathrm{V}$ shows the expected large overlap between the filter in the selection process of sea breeze days.

Table VI shows the overlap matrix for the rejected non-sea breeze days. The connection between the filters is evaluated by documentation of how many times the non sea breeze days are rejected by filters 1 and 2, filters 1 and 3, and so on. In Table VI the overlap between the filter is low, showing that the six filters are individually effective in filtering out non-sea breeze days. The strongest is filter 5 followed by filters 4 and 6, which are developed from observational studies of the sea breeze characteristic features, the change in wind direction and the temperature difference between land and sea.

\section{SUMMARY AND CONCLUSIONS}

The comparison between the simple method and the selection performed by the University of Lund, show that the method can extract a reasonably accurate data set without focusing on the physical processes active in the sea breeze development. The expected accuracy is more than $75 \%$ in the process of selecting sea breeze days. The six filters included in the method are individually important, especially filter 5 which represents the change in surface wind direction connected to the onset of the sea breeze. This filter showed the highest agreement with the Lund method in selection of sea breeze days (Table III).

This method will permit qualitative studies of the sea breeze development in an archipelago area using observational data. Here, the method is systematic and will present an objective data set to be used in studies of the physical processes responsible for the sea breeze development. The method also normalises the data, which enables comparisons between different areas and during different time periods to be accomplished.

Table IV. Comparison of non sea breeze days as selected by each filter versus the evaluation of the Lund method. Format is the same as Table III

\begin{tabular}{llrlll}
\hline Filter & \multicolumn{2}{l}{ Filter method } & & \multicolumn{2}{l}{ Lund method } \\
\cline { 2 - 3 } \cline { 5 - 6 } & Total days selected as sea breeze by the method & Sea breeze & & Possible sea breeze & Non-sea breeze \\
\hline 1 & 21 & 9 & 6 & 6 \\
2 & 21 & 7 & 8 & 6 & 21 \\
3 & 45 & 8 & 16 & 29 \\
4 & 66 & 15 & 22 & 36 \\
5 & 60 & 3 & 21 & 23 \\
6 & 55 & 12 & 20 & \\
\hline
\end{tabular}


Table V. Overlap matrix showing the degree of overlap between filters for the 50 days selected as sea breeze days by the Lund method. For example, filters 1 and 2 passed 37 days jointly as sea breeze days, etc

\begin{tabular}{|c|c|c|c|c|c|c|}
\hline Filter & $\mathbf{1}$ & $\mathbf{2}$ & $\mathbf{3}$ & $\mathbf{4}$ & $\mathbf{5}$ & $\mathbf{6}$ \\
\hline $\mathbf{1}$ & $\mathbf{4 1}$ & 37 & 33 & 29 & 39 & 32 \\
\hline $\mathbf{2}$ & 37 & $\mathbf{4 3}$ & 37 & 29 & 39 & 32 \\
\hline $\mathbf{3}$ & 33 & 37 & $\mathbf{4 2}$ & 30 & $\mathbf{4 0}$ & 32 \\
\hline $\mathbf{4}$ & 29 & 29 & 30 & $\mathbf{3 5}$ & 34 & 30 \\
\hline $\mathbf{5}$ & 39 & 39 & 40 & 34 & $\mathbf{4 7}$ & 38 \\
\hline $\mathbf{6}$ & 32 & 32 & 32 & 30 & 38 & $\mathbf{3 8}$ \\
\hline
\end{tabular}

Table VI. Overlap matrix showing the degree of overlap between filters for the 44 days selected as non sea breeze by the Lund method. For example, filters 4 and 5 jointly rejected 27 days, etc

\begin{tabular}{|c|c|c|c|c|c|c|}
\hline Filter & 1 & 2 & 3 & 4 & 5 & 6 \\
\hline 1 & 6 & 0 & 1 & 4 & 5 & 5 \\
\hline 2 & 0 & 6 & 3 & 6 & 5 & 5 \\
\hline 3 & 1 & 3 & 21 & 18 & 21 & 8 \\
\hline 5 & 5 & 5 & 21 & 27 & 36 & 17 \\
\hline 6 & 5 & 5 & 8 & 13 & 17 & 23 \\
\hline
\end{tabular}

The simplicity of the method allows improvements to be carried out easily, for example, if there is denser data available concerning the synoptic conditions. Because the method is as independent as possible from the physical processes responsible for the sea breeze development, the data set can be produced for validation of already existing sea breeze models.

\section{ACKNOWLEDGEMENTS}

We acknowledge, with appreciation, the co-operation and assistance of Professor J. O. Mattsson, Department of Physical Geography, University of Lund for his effort with the independent data set, and Professor S. Lindqvist for his support in discussions and comments on the manuscript. We are also 
grateful to Dr H. Hultberg at the Swedish Environmental Research Institute (IVL) for providing meteorological data, H. Alter for technical support in operating and maintaining scientific equipment and S. Svensson for drafting of figures.

\section{REFERENCES}

Arritt, R.W. 1992. 'Effects of the large-scale flow on characteristic features of the sea breeze', J. Appl. Meteorol., 32, $116-125$. Banfield, C.E. 1991. 'The frequency and surface characteristics of sea breezes at St. Johns, Newfoundland', Climatol. Bull., 25(1), $3-20$.

Banta, R.M. 1995. 'Sea breezes shallow and deep on the California coast', Mon. Wea. Rev., 123(12), 3614-3622.

Brittain, O.W. 1978. 'Forecasting sea-breezes at Eskmeals', Meteorol. Mag., 107, 88-96.

Gustavsson, T., Lindqvist, S., Borne, K. and Bogren, J. 1995. 'A study of sea and land breezes in an archipelago on the West Coast of Sweden', Int. J. Climatol., 15, 785-800.

Lyons, W.A. and Olsson, L.E. 1972. 'The climatology and prediction of the Chicago lake breeze', J. Appl. Meteorol., 11, $1254-72$. Mahrer, Y. and Pielke, R.A. 1977. 'The effect of topography on sea and land breezes in a two-dimensional numerical model', Mon. Wea. Rev., 105, 1151-62.

Neumann, J. and Mahrer, Y. 1971. 'A theoretical study of the land and sea breeze circulation', J. Atmos. Sci., 28, 532-42.

Physick, W.L. and Byron Scott, R.A.D. 1977. 'Observations of the sea breeze in the vicinity of a gulf', Weather, 32, 373-381.

Savijärvi, H. and Alestalo, M. 1988. 'The sea breeze over a lake or gulf as the function of the prevailing flow', Beitr. Phys. Atmos., 61(2), $98-104$

Watts, A. 1955. 'Sea breeze at Thorney Island', Meteorol. Mag., 84, 42-48.

Xian, Z. and Pielke, R.A. 1991. 'The effects of width of landmasses on the development of sea breezes', J. Appl. Meteorol., 30, $1280-1304$

Zhong, S. and Takle, E.S. 1992. 'An observational study of sea- and land- breeze circulation in an area of complex coastal heating', J. Appl. Meteorol., 31, 1426-1438. 